\title{
Microsurgical Management of Intracranial Aneurysms in Côte d'Ivoire: A Series of 128 Cases
}

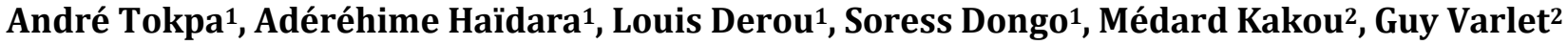 \\ ${ }^{1}$ Neurosurgery Department, Bouaké Teaching Hospital, Bouaké, Cote d'Ivoire \\ ${ }^{2}$ Neurosurgery Department, Yopougon Teaching Hospital, Abidjan, Cote d'Ivoire \\ Email:valentin_tokpa@yahoo.fr
}

How to cite this paper: Tokpa, A., Haïdara, A., Derou, L., Dongo, S., Kakou, M. and Varlet, G. (2020) Microsurgical Management of Intracranial Aneurysms in Côte d'Ivoire: A Series of 128 Cases. Open Journal of Modern Neurosurgery, 10, 105-113. https://doi.org/10.4236/ojmn.2020.101011

Received: September 23, 2019

Accepted: December 10, 2019

Published: December 13, 2019

Copyright $\odot 2020$ by author(s) and Scientific Research Publishing Inc. This work is licensed under the Creative Commons Attribution International License (CC BY 4.0).

http://creativecommons.org/licenses/by/4.0/

\begin{abstract}
Introduction: The management of intracranial aneurysms in sub-Saharan Africa is essentially surgical. In this retrospective study, the authors report their experience in surgical management of intracranial aneurysm in Côte d'Ivoire. Methods: We carried out a retrospective study on patients operated for a ruptured or unruptured intracranial aneurysm between January 1st, 2012 and December 31st, 2018. Data on epidemiological characteristics of patients and aneurysms, treatments and patient outcomes were analyzed. Results: One hundred twenty eight aneurysms were operated. Sixty-six percent of the patients were female. According to the World Federation of Neurosurgical Societies (WFNS) scale, 58, 5\% of patients were in grade I. Fisher scale showed $29 \%$ of Fisher 2 and $49 \%$ of Fisher 4 . The aneurysms were mainly located on the internal carotid artery in $38 \%$ and anterior complex in $36 \%$. The average size of aneurysms was $6.5 \mathrm{~mm}$. In $81.4 \%$ the size of the aneurysms was less than $10 \mathrm{~mm}$. Most aneurysms (90\%) were treated at late stage. According to the modified Rankin Scale, 92 patients (83\%) had good outcome, 7 patients $(6 \%)$ had poor outcome, and the mortality rate was $11 \%$. Conclusions: This study shows encouraging results if we refer to the overall postoperative results. However, there is a sub-diagnosis and low treatment rate of ruptured intracranial aneurysms. The improvement of intracranial aneurysms management requires improving the standard of health in the country.
\end{abstract}

\section{Keywords}

Intracranial Aneurysm, Microsurgery, Cote d'Ivoire, Subarachnoid Haemorrhage

\section{Introduction}

Microsurgery which has been for a long time the only treatment of intracranial aneurysms has been supplanted by endovascular treatment since the results of 
the International Subarachnoid Aneurysm Trial (ISAT) [1]. Currently endovascular treatment has become by far the first-line treatment of the great majority of ruptured and unruptured intracranial aneurysms. Some authors mention the end of surgical treatment of intracranial aneurysms [2].

In most sub-Saharan African countries, microsurgery remains the main treatment of intracranial aneurysms because of the unavailability of endovascular treatment. In most time, this microsurgery involves clipping or wrapping. Rarely other techniques including trapping or proximal artery occlusion by surgical ligation are performed. The timing of microsurgery after aneurismal subarachnoid haemorrhage is controversial.

In Côte d'Ivoire, a developing country in West Africa, surgery remained the only treatment of intracranial aneurysms until 2018, when endovascular treatment became part of the therapeutic arsenal in treatment of intracranial aneurysms in the country.

In this paper, authors reported the epidemiological characteristics of their patients, the characteristics of aneurysms and the result of their management.

\section{Patients and Methods}

We carried out a retrospective study on patients operated for one or more ruptured or unruptured intracranial aneurysm whom underwent microsurgical treatment of their aneurysm between January 1, 2012 and December 31, 2018. Of the 160 patients treated for intracranial aneurysm, 111 were retained. Other files were incomplete. Each patient had at least a CT head scan for the diagnosis of intracranial haemorrhage and CT angiography for the diagnosis of intracranial aneurysm. For each patient, data on age, sex, World Federation of Neurological Surgeon (WFNS) score at admission, Fisher grade, seat and size of the aneurysms, associated evolutionary complications (hydrocephalus, vasospasm, rebleeding), type of surgical treatment used, and quality of patient survival (assessed by Modified Rankin Scale at 1 year) were analyzed. The data collection and the making of graphs were made from excel. Statistical analyzes were performed on SPSS version 22 .

\section{Results}

According to the protocol, 111 patients with 128 operated aneurysms were selected.

\section{Age and sex}

Men accounted for $34 \%$ of patients versus $66 \%$ for women. The age of the patients ranged between 13 and 78 years old with a mean age and a median age of 46 years (Figure 1).

\section{Aneurysms characteristics}

A total of 128 aneurysms were diagnosed including 107 ruptured aneurysms and 21 unruptured aneurysms. These aneurysms were multiple in 15 patients (13.5\%). Aneurysms were present in the anterior cerebral circulation in $98.5 \%$ and in the posterior cerebral circulation in 1.5\% (Table 1). 


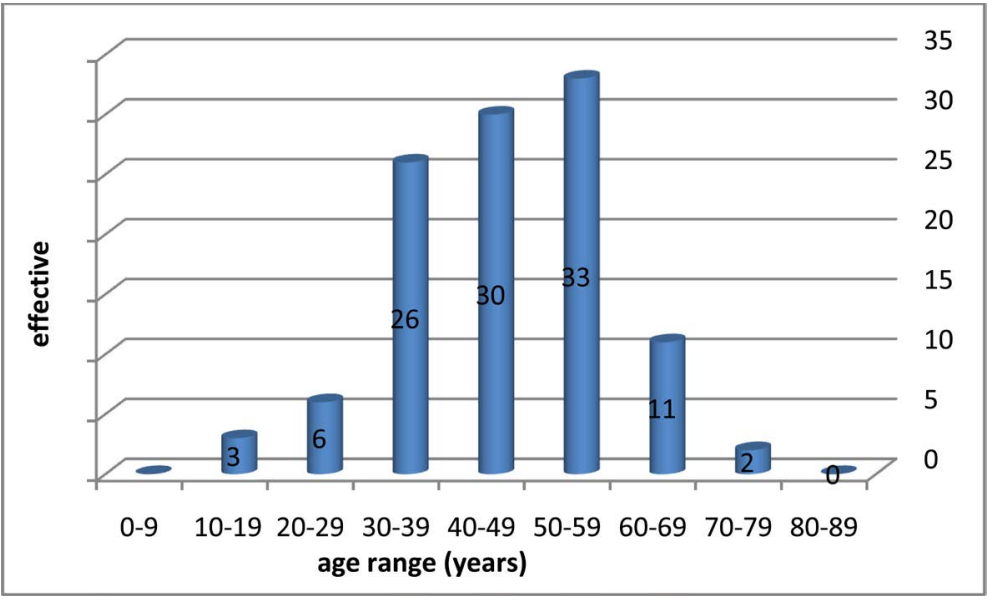

Figure 1. Distribution of patients according to the age.

Table 1. Distribution of aneurysms by anatomic location.

\begin{tabular}{|c|c|c|c|c|}
\hline & Right & Midline & Left & Total \\
\hline \multicolumn{5}{|l|}{ Anterior cerebral artery } \\
\hline Anterior communicating artery & & 33 & & 33 \\
\hline Proximal to anterior communicating & 3 & & 3 & 6 \\
\hline Pericallosal & 4 & & 3 & 7 \\
\hline Subtotal & 7 & 33 & 6 & 46 \\
\hline \multicolumn{5}{|l|}{ Internal carotid artery } \\
\hline Proximal or ophthalmic region & 1 & & 3 & 4 \\
\hline Posterior communicating region & 25 & & 17 & 42 \\
\hline Bifurcation & 2 & & & 2 \\
\hline Cavernous internal carotid & 1 & & & 1 \\
\hline Subtotal & 29 & & 20 & 49 \\
\hline \multicolumn{5}{|l|}{ Middle cerebral artery } \\
\hline Bifurcation & 16 & & 10 & 26 \\
\hline Distal to main bifurcation & 3 & & 2 & 5 \\
\hline Subtotal & 19 & & 12 & 31 \\
\hline \multicolumn{5}{|l|}{ Posterior circulation } \\
\hline Basilar bifurcation & & 1 & & 1 \\
\hline Posterior cerebral artery & 1 & & & 1 \\
\hline Subtotal & 1 & 1 & & 2 \\
\hline Total & 56 & 34 & 38 & 128 \\
\hline
\end{tabular}

Of the 107 ruptured aneurysms, 33 were located in the anterior communicating artery, 32 were located in the internal carotid artery and 27 in the middle cerebral artery. Aneurysms were sacciform in 123 cases (96\%) versus 5 fusiform aneurysms (4\%).

The average size of the aneurysms was $6.5 \mathrm{~mm}$ with extremes of 2 and $27 \mathrm{~mm}$. The size of the aneurysms was less than $10 \mathrm{~mm}$ in $81.4 \%$ of cases and 2 cases of giant aneurysm (size greater than $25 \mathrm{~mm}$ ) were operated. 


\section{Preoperative condition}

The WFNS grade is shown in the histogram below with a clear predominance of grade 1 (58.5\%) (Figure 2).

Cerebral CT scan was able to classify the patients according to Fisher score with a clear predominance of grade 4 (Figure 3 ).

The WFNS score at the time of surgery was 0 in 4 patients, 1 in 94 patients, 2 in 4,3 in 8 and 4 in 1 patient.

\section{Timing of surgery and overall surgical result}

The average time between rupture and surgical exclusion was 31 days with a range from 1 to 180 days. One hundred and fifteen (90\%) aneurysms were treated 8 days or more after rupture. Only ten aneurysms (8\%) were operated within 72 hours and $3(2 \%)$ between 4 and 7 days after aneurysmal rupture. While waiting for surgical treatment 14 (12.6\%) patients survived rebleeding, 17 (15.3\%) cases of acute and chronic hydrocephalus were observed, 2 cases of delayed ischemia.

Surgical treatment consisted of clipping in 118 (92\%) aneurysms versus 10 (8\%) wrapped aneurysms.

During surgery 20 cases of intraoperative aneurysm rupture occurred. Immediate postoperative complications occurred in some patients. Six (5.4\%) operative

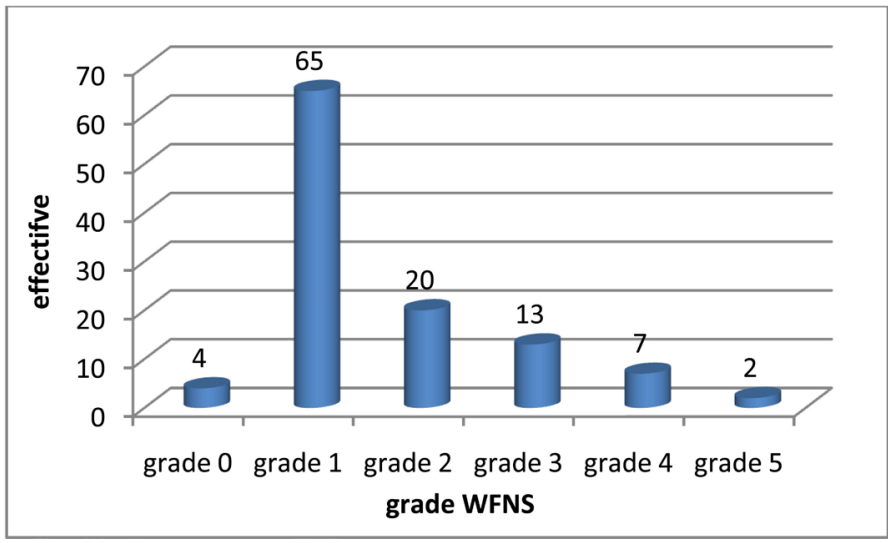

Figure 2. Distribution of patients according to the WFNS score.

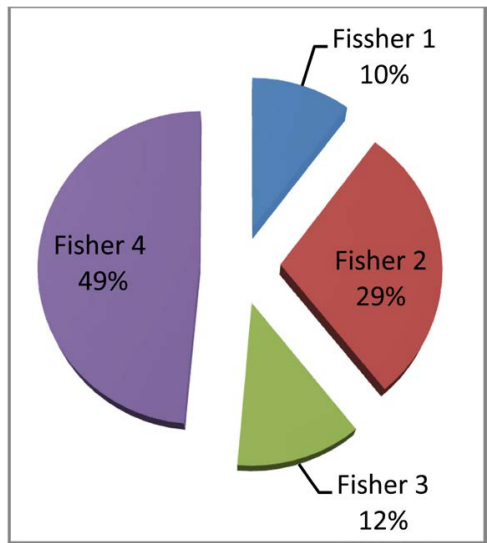

Figure 3. Distribution of patients according to the Fisher score. 
revisions were performed for early postoperative complications, including 4 extradural hematomas and 2 cases of malignant cerebral oedema.

CT angiography after microsurgery was performed in 61 patients with clipped aneurysms and revealed complete exclusion in all cases.

A good mRs (modified Rankin Scale) score was observed in 92 (83\%) patients, a poor score in $7(6 \%)$. The mortality rate was $11 \%$, i.e. 12 patients (Table 2).

No case of rebleeding occurred after at least 1 year follow-up.

Sequel of epilepsy was observed in $5(4.5 \%)$ patients.

\section{Discussion}

Although there are very few publications about intracranial aneurysms in Africa, particularly in sub-Saharan countries, intracranial aneurysms are not uncommon [3] [4] in this part of the word. Surgery remains the only therapeutic modality available in several African countries.

\section{Age and sex}

Our study population consisted mainly of young adults with an average age of 46 years. Thioub et al. found in their study, in Senegal, an average age similar to ours (45.9 years) [3]. The average age of patients in the ISAT study was 52 years [1]. The average age of our patients is lower than those of the ISAT study $(t=$ $-5.135, \mathrm{ddl}=110$, confidence interval -8.47 to $-3.7595 \%)$. In our series the peak of incidence is reached a decade rather (4th and 5th decades) than in most studies where this peak is between the 5th and 6th decade [1] [5] [6] [7]. This could be explained in part by the characteristics of the Ivorian population:

- essentially young population,

- low life expectancy (ranging from 46.6 years in 2000 to 53.5 years in 2016) [8].

A predominance of females is generally reported in most studies [6] [7] [9]. It was also observed in ours (66\%). ISAT study found $37 \%$ of male and $63 \%$ of female [1].

Britz Gavin, W. et al. reported a clear predominance of female (66.3\%) in their study [10].

Table 2. Patients outcomes according to WFNS score.

\begin{tabular}{cccc}
\hline WFNS at admission & Good outcomes (mRS 0 - 2) & Poor outcomes (mRS 3 - 5) & Mortality; \\
\hline 0 & 3 & 1 & 0 \\
I & 54 & 5 & 6 \\
II & 17 & 0 & 3 \\
III & 11 & 0 & 2 \\
IV & 5 & 1 & 1 \\
V & 2 & 0 & 0 \\
TOTAL & 92 & 7 & 12 \\
\hline
\end{tabular}

WFNS, World Federation of Neurosurgical Societies. 
Several explanations of the female predominance of aneurysmal subarachnoid haemorrhage have been discussed in the literature. Because the incidence is highest in women after menopause, it has been suggested that female sex hormones may play a key role in the formation and growth of intracranial aneurysms [11] [12] [13]. According to Okamoto et al. [13] the occurrence of menopause at a relatively low age and/or nulliparity are associated with an increased risk of subarachnoid haemorrhage, including aneurysmal rupture, in contrast a high number of pregnancies and multiparity would be protective factors. This phenomenon is explained by the high level of progesterone during pregnancy, which causes progesterone-oestrogen ratio in favour of progesterone. Early menopause and nulliparity are associated with elevated estradiol levels. Oestrogen promotes elevated blood pressure and decreased vascular resistance. It is clear therefore that progesterone is a protective element against the risk of vascular injury. It is thus understood that the drop in her rate after menopause exposes the woman to vascular lesions in general and particularly to subarachnoid haemorrhages by aneurismal rupture. This explains the female predominance of subarachnoid haemorrhage by aneurysmal rupture after the age of menopause.

\section{Aneurysm Characteristics \\ Aneurysm locations}

The international subarachnoid aneurysm trial (ISAT) found that $95 \%$ of aneurysms were located in the anterior cerebral circulation [1]. In our series $98.5 \%$ of the operated aneurysms were located in the anterior cerebral circulation. This could be explained by the fact that the aneurysms of the posterior cerebral circulation, which are easily amenable to endovascular treatment, have been rejected by surgery. The distribution of ruptured aneurysms according to their location varies according to the studies. In our series, the ruptured aneurysms that we operated were as much found in the anterior communicating artery as in the internal carotid artery. The predominant seat of ruptured aneurysms varies according to studies. However, most studies like ISAT [1] and Thioub study [3] report a predilection at the anterior communicating artery.

\section{Form of aneurysms}

We observed a high prevalence of sacciform aneurysms $96 \%$ against only $4 \%$ for fusiform aneurysms. Thioub et al. reported $92.3 \%$ of sacciform aneurysms and $7.7 \%$ fusiform aneurysm in their series [3].

\section{Size of aneurysms}

Many studies have attempted to determine a critical size at which an aneurysm is likely to rupture and thus justify its treatment.

In our series, the average size of aneurysms was $6.5 \mathrm{~mm}$. The sizes of the aneurysms were less than $10 \mathrm{~mm}$ in $81.4 \%$. Thioub et al. observed that $73 \%$ of operated aneurysms were smaller than $10 \mathrm{~mm}[3]$.

\section{Preoperative condition}

The major clinical manifestation of intracranial aneurysms is subarachnoid haemorrhage, which is the first manifestation in more than $90 \%$ of cases [14]. 
This aneurysmal rupture with onset of intracranial haemorrhage was the most common finding (96.5\%) in our series.

\section{Timing of surgery and overall surgical result}

Despite the progress made in the surgery of intracranial aneurysms, there is no consensus about the optimal time for performing this surgery in order to obtain the best results in ruptured aneurysm. The work of Nieuwakamp, D.J. et al. [15] and Zhao, C. et al. [16] failed to prove the influence of surgical timing on patient outcomes. Yao, Z. et al. [17] in their study observed that early surgery was superior to late surgery in reducing a poor outcome and death rate when patients were in good condition on admission, and decreased the incidence of poor outcome when patients were in poor condition on admission.

The majority of our patients were operated at the late stage for several reasons:

- delayed diagnosis especially for late consultation,

- financial difficulty because there is no national social security and care is in most cases the responsibility of the patient,

- the current protocol in our service recommends to operate the patient either within 3 days following the rupture or beyond the 15th day.

We recommend early surgery to prevent early rebleeding especially since it does not seem harmful to the patient.

\section{Aneurysm surgery}

Most authors, like Lafuente [6] and Thioub [3], report that clipping is by far the most commonly surgical technique used in intracranial aneurysm surgery. This technique was used in $92 \%$ of the aneurysms we treated.

\section{Conclusions}

This study shows encouraging results if we refer to the overall postoperative results. However, there is a sub-diagnosis and a low treatment rate of ruptured intracranial aneurysms because of the weakness of the country's health system.

The improvement of intracranial aneurysms management requires the establishment of national social coverage and improvement of the technical platform of the health structures in the country.

\section{Conflicts of Interest}

The authors declare that the article content was composed in the absence of any commercial or financial relationships that could be construed as a potential conflict of interest.

\section{References}

[1] Molyneux, A.J., Kerr, R., Stratton, I., Sandercock, P., Clarke, M., Shrimpton, J., et al. (2002) International Subarachnoid Aneurysm Trial (ISAT) of Neurosurgical Clipping versus Endovascular Coiling in 2143 Patients with Ruptured Intracranial Aneurysms: A Randomised Trial. The Lancet, 360, 1267-1274. https://doi.org/10.1016/S0140-6736(02)11314-6

[2] Maurice-Williams, R.S. and Lafuente, J. (2003) Intracranial Surgery and Its Future. 
Journal of the Royal Society of Medicine, 96, 540-543.

[3] Thioub, M., Mbaye, M., Thiam, A.B., Zirhumana, C., Sy, C., Ndoye, N., Ba, M.C. and Badiane, S.B. (2018) Microsurgical Treatment of Ruptured Intracranial Aneurysms in Sub-Saharan Africa: A Series of 102 Consecutive Cases Treated in Senegal. World Neurosurgery, 110, 226-231. https://doi.org/10.1016/j.wneu.2017.11.048

[4] Mudjir, B.D., Quenum, K., Boutarbouch, M., Arkha, Y., Derraz, S., El Ouahabi, A., et al. (2006) Les anévrysmes cérébraux ne sont pas rares au Maroc et probablement en Afrique. Notre expérience sur une série de 354 cas [Brain Aneurysms Are Not Uncommon in Morocco and Probably in Africa. Our Experience on a Series of 354 Cases]. Neurochirurgie, 52, 471. https://doi.org/10.1016/S0028-3770(06)71260-7

[5] The ACROSS Group (2000) Epidemiology of Aneurysmal Subarachnoid Hemorrhage in Australia and New Zealand: Incidence and Case Fatality from the Australasian Cooperative Research on Subarachnoid Hemorrhage Study (ACROSS). Stroke, 31, 1843-1850. https://doi.org/10.1161/01.STR.31.8.1843

[6] Lafuente, J. and Maurice-Williams, R.S. (2003) Ruptured Intracranial Aneurysms: The Outcome of Surgical Treatment in Experienced Hands in the Period Prior to the Advent of Endovascular Coiling. Journal of Neurology, Neurosurgery \& Psychiatry, 74, 1680-1684. https://doi.org/10.1136/jnnp.74.12.1680

[7] Lai, H.P., Cheng, K.M., Yu, S., Yeung, A.K.M., Cheung, Y.L., Chan, C.M., Poon, W.S. and Lui, W.M. (2009) Size, Location, and Multiplicity of Ruptured Intracranial Aneurysms in the Hong Kong Chinese Population with Subarachnoid Haemorrhage. Hong Kong Medical Journal, 15, 262-266.

[8] Banque mondiale (2019) Espérance de vie. https://www.google.fr/publicdata

[9] Rinkel, G.J., Djibuti, M., Algra, A. and van Gijn, J. (1998) Prevalence and Risk of Rupture of Intracranial Aneurysms: A Systematic Review. Stroke, 29, 251-256. https://doi.org/10.1161/01.STR.29.1.251

[10] Britz, G.W., Salem, L., Newell, D.W., Eskridge, J. and Flum, D.R. (2004) Impact of Surgical Clipping on Survival in Unruptured and Ruptured Cerebral Aneurysms: A Population-Based Study. Stroke, 35, 1399-1403. https://doi.org/10.1161/01.STR.0000128706.41021.01

[11] Gaist, D., Pedersen, L., Cnattingius, S. and Sorensen, H.T. (2004) Parity and Risk of Subarachnoid Hemorrhage in Women: A Nested Case-Control Study Based on National Swedish Registries. Stroke, 35, 28-32. https://doi.org/10.1161/01.STR.0000105933.16654.B4

[12] Johnston, S.C., Colford, J.M. and Gress, D.R. (1998) Oral Contraceptives and the Risk of Subarachnoid Hemorrhage: A Meta-Analysis. Neurology, 51, 411-418. https://doi.org/10.1212/WNL.51.2.411

[13] Okamoto, K., Horisawa, R., Kawamura, T., Akihiko, A., Masataka, O., Takuya, T. and Yoshiyuki, O. (2001) Menstrual and Reproductive Factors for Subarachnoid Hemorrhage Risk in Women: A Case-Control Study in Nagoya, Japan. Stroke, 32, 2841. https://doi.org/10.1161/hs1201.099383

[14] Meyer, F.B., Morita, A., Puumala, M.R. and Nichols, D.A. (1995) Medical and Surgical Management of Intracranial Aneurysms. Mayo Clinic Proceedings, 70, 153-172. https://doi.org/10.4065/70.2.153

[15] Nieuwkamp, D.J., de Gans, K., Algra, A., Albrecht, K.W., Boomstra, S., Brouwers, P.J., Groen, R.J., Metzemaekers, J.D., Nijssen, P.C., Roos, Y.B., Tulleken, C.A., Vandertop, W.P., van Gijn, J., Vos, P.E. and Rinkel, G.J. (2005) Timing of Aneurysm Surgery in Subarachnoid Haemorrhage-An Observational Study in The Netherlands. Acta Neurochirurgica, 147, 815-821. 
https://doi.org/10.1007/s00701-005-0536-0

[16] Zhao, C. and Wei, Y. (2017) Surgical Timing for Aneurysmal Subarachnoid Hemorrhage: A Meta-Analysis and Systematic Review. Turkish Neurosurgery, 27, 489-499.

[17] Yao, Z., Hu, X., Ma, L., You, C. and He, M. (2017) Timing of Surgery for Aneurysmal Subarachnoid Hemorrhage: A Systematic Review and Meta-Analysis. International Journal of Surgery, 48, 266-274. https://doi.org/10.1016/j.ijsu.2017.11.033 